\title{
CARTOGRAFII ALE MEMORIEI ÎN PROZA RUXANDREI CESEREANU ȘI A TATIANEI ȚÎBULEAC
}

\author{
Gabriela-Emilia Merce, Master II \\ Universitatea de Vest din Timişoara
}

\begin{abstract}
The starting point of my study is represented by two works, Grădina de sticlă (Tatiana Țîbuleac) and Un singur cer deasupra tuturor (Ruxandra Cesereanu). These are two novels that organize their narrative discourse following the relation trauma-memory-identity. In fact, Tatiana Țîbuleac and Ruxandra Cesereanu emphasize in their proses how can a social identity be recreated, when everybody feels the terror enforced by the authority. In this case, when you lose everything, you become vulnerable and this feeling causes the alienation, the break. Therefore, in this paper, we will show how the memory reopens the dialogue with the past, more exactly with a traumatic past. We will illustrate also the fact that in the process of remembering the space changes the identitary their attributes.
\end{abstract}

\section{Keywords}

postcommunism, memory, trauma, identity, literature

\section{În căutarea unei direcții}

Discursul despre proza românească contemporană din ultimele decenii urmărește de cele mai multe ori identificarea unor direcții tematice în ceea ce o privește. În acest sens, studiile critice identifică înainte de toate un tip de proză care coboară în real, în banalul cotidian, cu precădere, și care întreține discuția despre existența unui tipar neorealist, ce proiectează duritatea prezentului, astfel încât „ocultând istoria, romanul contemporan a preferat o anumită indiferență la procesele complexe ale memoriei, alegând deseori să urmărească realitatea imediată, adică modul în care a reacționat societatea la fenomenul tranziției." . Narațiunile vor refuza, în consecință, imediat după căderea comunismului, „tema obsedantei revoluții ca și pe cea a obsedantului comunism, propunând, în schimb, propriile teme, furnizate de libertatea de călătorie, libertatea sexuală, dezamăgiri și detabuizări’”2.

O astfel de proză pătrunde în realitatea imediată și preia comportamente pe care le transpune în actul narării printr-o denudare a limbajului, exegeza definind proza contemporană românească în 
relație cu termenii-umbrelă minimalism, respectiv mizerabilism în contextul identificării unei specificităţi a literaturii de după 2000, care să-i legitimeze autenticitatea în raport cu literatura de până atunci. Alex Goldiș afirma, de altfel, în cadrul unui dialog cultural, că „Este foarte greu de făcut o panoramă a prozei de după 2000 [...] însă, câteva direcții centrale [...] pot fi delimitate"’3, și anume: există o proză care își trasează cadrele în cotidianul banal, definită fiind și printr-o ,formulă biografistă"4 (ca de exemplu narațiunile lui Adrian Schiop, Ioana Baetica etc.), precum și una care preferă reîntoarcerea la poveste (ca în cazul romanelor scrise de Florina Ilis sau de Lucian Dan Teodorovici, autori care preferă o construcție narativă mai amplă, fluidă). În același context, Vasile Spiridon amintește de prezența unei proze erotice, a unei proze despre identităţile la ,graniţă”, întâlnite la autori precum Cecilia Ștefănescu, Alexandru Vakulovski etc. Printr-o astfel de literatură, instinctualitatea este revelată şi, mai mult decât atât, se înscrie în acel tip de proză care „funcționează pe dimensiunea «prezentismului»."5. Totodată, Oliver Anghel menţionează în studiul Proza de creație a generaţiei 2000 că „Discursul autenticist al douămiiștilor denunță programatic atracția pentru obscenitate [...], încercând să exorcizeze, astfel, agresivitatea și violența existenţială, printr-o amorsare vizionară.”6. Tot el mai remarcă: „O tendință interesantă a prozei actuale este literatura pentru copii." ${ }^{\prime 7}$, cea care își construiește un discurs narativ în jurul temei copilăriei, dar care nu e destinată copiilor, romanul Florinei Ilis Cruciada copiilor sau al lui T. O. Bobe Cum miam petrecut vacanța de vară fiind exemplele propuse de Anghel, la care putem adăuga romanul lui Radu Pavel Gheo, Noapte bună, copii!.

Însă, pe fondul experienței traumatice a veacului trecut, care a contribuit la perpetuarea unei stări de pierdere, există și o dimensiune a prozei ultimelor decade, care este susținută de preferința pentru o literatură a memoriei, întrucât „«Toate marile opere de artă central-europene ale acestui secol, inclusiv cele din zilele noastre, pot fi înțelese ca fiind lungi meditații pe tema sfârşitului umanității.»»" ${ }^{\prime}$. Amintirea trecutului va deveni în fapt o acțiune voluntară, care derivă din necesitatea perpetuării unei identități pe de o parte, iar, pe de altă parte, este ,un gest cu caracter proiectiv, care se petrece întotdeauna în prezent"9. Memoria a funcționat și funcționează deci ca un nucleu care generează coerență prezentului, întrucât aceasta reflectă coordonatele primare în ceea ce privește dialogul cu celălalt. Totodată, memoria creează în imaginarul colectiv un spațiu de referință, care va permite relaționarea cu alteritatea.

De aceea, în plan cultural, având în vedere tensiunea pe care a generat-o secolul trecut și, mai mult decât atât, trauma pe care a provocat-o, este de așteptat ca literatura să se ralieze la noul climat socio-cultural. Ion Bogdan Lefter enunță în primele pagini ale studiului Despre identitate. Temele postmodernității că ,diversitatea ține de însăși structura postmodernității, de multiplicitatea discursurilor ei." ${ }^{\prime 10}$. Așadar, refuzul memoriei sau pactul cu memoria animă spațiul socio-cultural printr-o dinamică specifică. Lefter mai semnalează, de altfel, că subiectele care suscită spațiul 
academic, mai ales, sunt multiculturalismul, postcomunismul, modelul cultural, respectiv metamorfoza canonului. Rezultă așadar că într-o epocă a transmutărilor, a transformărilor și a tranziției, memoria este cea care asigură conexiunea cu vechiul model, întrucât „Traumele secolului, relaţia ingrată cu trecutul, experiențele degenerante de înţelegere a propriei genealogii au contribuit la o necesitate crescândă de reconfigurare a istoriografiilor, importanței mărturiilor și reprezentărilor." $"$.

Literatura memoriei va transgresa așadar actul narării, ilustrând valenţele cultural-istorice, întrucât „Relația cu memoria, cu uitarea, legătura indisolubilă public-privat sunt un joc în analizele narațiunilor traumei care permit accesul cititorilor la experiența traumatică."12, prin astfel de narațiuni redându-se, de fapt, trecutul ascuns de o istorie falsificată. Se va institui, din acest punct de vedere, un cult al amintirii, care va avea drept obiectiv depășirea rupturii prin refacerea într-un plan imaginar a unei traume colective, al sentimentului înstrăinării. Astfel, ,eforturile de a depăşi şocul schimbării de paradigmă se translatează într-o amplă literatură a confesiunii, o literatură a martorilor şi a mărturiei, aşa cum s-a întâmplat în prima decadă după sfârşitul celui de-al doilea război mondial (sic!), unde evenimentul traumatic era revelarea publică a ororilor Holocaustului, mai apoi şi a Gulagului." "13. Totodată, Sanda Cordoș afirmă în studiul Lumi din cuvinte: reprezentări și identități în literatura postbelică faptul că „trecerea de la o lume la alta, de la dictatură la postcomunism, este o problemă cardinală și pun propria artă în primul rând în slujba acestei investigaţii”"14.

Rememorarea va determina, prin urmare, crearea unui discurs specific, definit printr-un algoritm simplu, care prevede o relație de interdependență între memorie, cultură și societate. Această reprezentare tripartită constituie și punctul de plecare al lucrării lui Paul Ricoeur, care în lucrarea Memoria, istoria, uitarea propune definirea memoriei din perspectiva dublei raportări: memoria e evocare, dar este și căutare sau reamintire ${ }^{15}$, existând o memorie care repetă, respectiv una care imaginează. Asemănător, Maurice Halbwachs în studiul Memoria colectivă va distinge două tipuri: există o memorie individuală, respectiv una colectivă ${ }^{16}$. Mult mai pragmatic, Foster afirmă: „Fără memorie, noi nu am fi capabili să vorbim, să citim, să identificăm obiectele ce ne înconjoară, să călătorim sau să întreținem relații personale" ${ }^{17}$. Astfel, memoria ordonează relațiile interumane, stabilind o legătură între ceea ce se vede și ceea ce se ințelege. De aceea „Recuperarea memoriei este cel mai complex proces al postcomunismului." ${ }^{\prime 18}$, literatura devenind un instrument predilect pentru reprezentarea trecutului.

Romane precum Un singur cer deasupra tuturor sau Grădina de sticlă vor reflecta, în definitiv, o lume dezrădăcinată, a nonsensului, gravitată de personaje-idee, care configurează o memorie colectivă. Astfel, „Nu istoria a însemnat nucleul de interes al prozatorilor în postcomunism, ci memoria individuală și apoi cea colectivă, iar când ne referim la memorie, ne gândim 
la modul ei de a opera, la mecanismul care permite recuperarea unui trecut atât de bine camuflat în istoria falsificată."19. În lucrarea de față, vom urmări felul în care Ruxandra Cesereanu și Tatiana Țîbuleac își construiesc discursul narativ despre identitate și alteritate în raport cu memoria, care formează o atât o identitate socială, cât și una culturală. Astfel, vom arăta că „romanul românesc postcomunist redescoperă rolul memoriei literare, expunând personaje care deconstruiesc istoria falsificată și efectele sale asupra omului." ${ }^{20}$, întrucât atât Cesereanu în romanul Un singur cer deasupra tuturor, cât și Țîbuleac în Grădina de sticlă propun formule narative care să ilustreze impactul pe care memoria îl are în definirea unei identităţi primare.

Romanul lui Cesereanu și cel al lui Țîbuleac radiografiază un trecut recent asemeni lui Dan Lungu în Sunt o babă comunistă, lui Radu Pavel Gheo în Noapte bună copii! sau asemeni lui Bogdan Suceavă în Noaptea când cineva a murit pentru tine. Dacă în cazul lui Cesereanu, perspectiva documentaristă este puternic vizibilă, romanul acesteia fiind constituit dintr-o serie de reprezentări care configurează, prin structura cinematografică, o imagine revelatoare despre comunism, în cazul lui Țîbuleac țesătura narativă oferă ritmicitate și poveste discursului.

\section{Memoria lor, a tuturor}

Referitor la romanul lui Cesereanu, Andrei Simuț consideră că Un singur cer deasupra tuturor reprezintă „o summa a istoriei şi trăsăturilor trecutului comunist.”21. „Camera” se deplasează constant la Cesereanu și urmărește destine individuale, dar sunt destine care au în comun același spaţiu de referință. E un spațiu care împiedică relaționarea deschisă, necenzurată cu celălalt. Astfel, deși fiecare capitol al romanului ilustrează experiența unui alt personaj în relație cu dictatura comunistă, de fapt, istoriile personale, mărturiile se completează reciproc, oferind o imagine complexă despre felul în care s-a articulat în memoria individuală, iar mai apoi în cea colectivă, imaginea realităţii comuniste.

Astfel, având „,comunismul drept personaj-cadru, asumându-1 ca pe o stare firească, ca pe o forţă a naturii, distantă şi de neînţeles, ca pe un decor fascinant unde viaţa poate să se desfăşoare în ritmurile ei" 22 , în romanul Ruxandrei Cesereanu memoriile individuale vor perpetua o memorie colectivă aflată în disonanţă cu realitatea prefabricată prin discursul istoriilor. Capitolul intitulat Lucreția va reflecta, din acest punct de vedere, pe de o parte, strategiile pe care autoritatea le-a urmat cu scopul de a impune un sistem de gândire unic, mutilarea unei memorii individuale care transmite intergenerațional valori şi atitudini primare reprezentând principalul obiectiv în formarea unei noi societăți. Pe de altă parte, Lucreția prezintă o lume dezintegrată, un spațiu vid al memoriei, golit de imagine, în care cunoscutul este de nerecunoscut, întrucât „Când se întorseseră acasă din război și din refugiu satul era plin de buruieni și de șobolani [...]. Oamenii nu plângeau însă, ci 
râdeau de şobolanii ăia: satul nu mai era ocupat de nemți sau de ruși, ci de șobolani."23. Deși această realitate este mai întâi acceptată, aceasta urmează a fi greu de suportat odată cu impunerea noii ordini politice, deoarece ,într-o seară, când tovarășii în haine de piele și cu băști negre pe cap îl ridicaseră din casă pe bătrân Lucreția pricepu ce era de priceput: trebuia să fugă undeva și unde altundeva decât în munți." ${ }^{24}$. Ruxandra Cesereanu va opera așadar în romanul său cu mărturiile celor care și-au expus public o memorie individuală traumatizantă, construindu-și sistematic discursul narativ prin preluarea unor imagini-simbol grefate în memoria colectivă, pe care le revizitează prin atribuirea acestora memoriilor individuale, personale. În acest fel, memoriile individuale vor surprinde acea generalizare a deviației și instituirea acesteia ca normă.

Încă din primele pagini, narațiunea se dezvoltă la Cesereanu în jurul marilor teme care fac trimitere la regimul comunist, și anume rezistența în munți sau instituționalizarea violenței. Din acest punct de vedere, cartografierea unei memorii colective formate sub dictatura comunistă impune identificarea factorilor care au subjugat-o. Astfel, opresiunea (Lucreția), persecuția (Leontin), munca silnică (Alexandru), instituționalizarea violenței, înfometarea, dezrădăcinarea (Johann sau Padre Basilio), instituirea unei neîncrederi în celălalt (Anda), crearea unei societăţi rigide în care libertatea de exprimare era cenzurată (Valeriu) au dat naștere unei memorii colective traumatice și unor identități în ruptură în lipsa unui dialog cu alteritatea.

În romanul Ruxandrei Cesereanu identificăm, de altfel, o preferință pentru categoria vulnerabililor, întrucât metamorfoza unei memorii colective este determinată de generalizarea sentimentului nesiguranței, rezultând o destabilizare de la centru a socialului. Personajele vulnerabile sunt cele care devin victimele sistemului, fiind colportorii unei memorii fabricate, care consideră diferitul un pericol ce trebuie anihilat. Capitole din roman precum Tinu sau Patiuşa prezintă destinele unor personaje ce acţionează împotriva vechii ordini pe care o definesc ca nefirească, malignă. Analizând cele două capitole amintite anterior, vom observa că Cesereanu se raportează constant la structurile narative pe care memoria colectivă le-a înregistrat. Astfel, violenţa devine un factor inhibator pentru cei care resimt opresiunea, dar pentru cei care o promovează reprezintă o validare a rolului pe care îl dețin în formarea, definirea omului nou. Personajului Tinu, din capitolul care-i împrumută numele, ,îi plăcea aventura asta, să vâneze dușmani ai poporului, fiindcă se simțea puternic și tânăr.” ${ }^{25}$ şi ,,se mira în sinea lui de femeia aceea. Ce căuta ea pe munte? Era sănătoasă la minte?"26. Deci, pentru Tinu nu el reprezenta deviația în raport cu ceilalți, ci, dimpotrivă, cei care se opun sistemului. Patiușa, din capitolul omonim, îl va surclasa pe Tinu în ceea ce privește îndoctrinarea comunistă, întrucât „nu făcuse altceva decât ce îi ceruse Partidul. Să faci moarte de om nu era așa o catastrofă: în viață trebuie să faci și moarte de om. Iar el nu simţise nimic atunci. Nu simţise că omoară pe cineva cu ranga ori cu bolovanul, ci doar face un lucru necesar și adevărat împotriva acelei cărni care era moale și scârboasă."27. Mai mult decât atât, 
acesta găsește necesară instituționalizarea violenței, deoarece „Fără ură de clasă nu s-ar fi putut munci la crearea unui astfel de organ sănătos." ${ }^{28}$.

\section{Identitate și identități}

În ceea ce o privește pe Tatiana Țîbuleac, spre deosebire de Cesereanu care reconstituie un trecut traumatic prin suprapunerea unor mărturii-cheie, aceasta preferă să reprezinte realitatea comunistă prin coborârea în intimitatea personajului feminin Lastocika. De altfel, dacă Cesereanu urmărește metamorfozele unei identități socio-culturale care determină o identitate personală, în cazul lui Țîbuleac, mai importantă este identitatea personală, primară, traumatică. Astfel, în romanul Tatianei Țîbuleac „Trauma biografiei pierdute este compensată prin recuperarea memoriei personale și ficționalizarea acesteia” ${ }^{29}$, fapt remarcat încă din incipitul romanului, deoarece „Mă nasc noaptea, am şapte ani. M-ar lua în brațe, însă are mâinile ocupate." ${ }^{\text {30 }}$.

Grădina de sticlă urmărește așadar destinul unei fete care crește între două limbi și între două culturi, context care generează, în fapt, o memorie traumatică și, în același timp, o identitate în ruptură. Lastocika, personajul feminin în jurul căruia este țesut discursul narativ, reflectă compasiunea pentru suferință, ceea ce rezultă şi din următoarea secvență: „Nicio altă dimineață nu a fost ca aceea, prima, când m-am trezit în patul ei. Dormisem exact pe mijloc, ca o umplutură. Cinci fete ar fi încăput lângă mine dacă ne-am fi culcat toate de-a curmezișul [...]. La internat aveam doar o pătură. A mea mirosea a șoareci, dar se putea și mai rău."31. Observăm că la Țîbuleac până și asocierile lexicale trădează o identitate multiplă care se metamorfozează de îndată ce resimte constrângerile unei memorii colective, care se impune memoriei personale. Structuri de tipul „M-ar lua în brațe, dar are mâinile ocupate.”32, „Dormisem exact pe mijloc, ca o umplutură.”33, ,aveam doar o pătură"34 trădează o identitate vulnerabilă, manipulabilă, ușor de supus unei epuizări fizice, întrucât copila Lastocika este doar instrumentul care i-ar putea oferi Tamarei Pavlovna stabilitate economică.

Mai mult decât atât, romanul Tatianei Țîbuleac prezintă factorii care impun un cod identitar comun unui grup social, însă, în momentul în care schimbările geopolitice retrasează granițele unui stat, vom constata faptul că memoriile vor impune o identitate în ruptură, întrucât nu mai există o comunicare nealterată cu trecutul. În acest sens, relaţia cu spațiul va genera un tipar cognitiv specific, înregistrat de o identitate personală. Raportându-ne la romanul Grădina de sticlă, remarcăm că structuri narative de tipul „Există în Chișinău o stradă - cea mai lungă și mai anevoioasă stradă din lume. Pe strada aceea, clădirile, copacii, semafoarele, chiar și lăzile de gunoi, chiar și gropile, știu cuvinte în limba rusă. O singură dată mi-a spus: decât să vorbesc ca o proastă rusește, mai bine să vorbesc moldovenește." ${ }^{\prime 35}$ reflectă o problemă în ceea ce privește asumarea unui 
cod identitar când realitatea istorică impune un alt sistem valoric și cultural. Trecerea de la o administrație politică la o altă guvernare în decursul câtorva ani produce o instabilitate redată de apariţia unor structuri culturale hibride în care limbile se amestecă și încearcă să se domine reciproc. Astfel, se va institui o generalizare a deviației de la codul identitar primar, întrucât acesta nu mai oferă siguranță socială.

În același context, definirea identității în relație cu limba vorbită va impune perspective multiple. Vom observa că, în cazul Lastocikăi, a crește între două limbi înseamnă a determina crearea unui spațiu-punte, care presupune a fi mereu între. Secvența „Prin aprilie începusem să primesc mai puține triunghiuri în frunte. Puteam să cumpăr de la magazin câte ceva fără a mă face de rușine. Deși toate vânzătoarele înțelegeau moldovenește, de vorbit nu vorbea niciuna. Moldovenii, în schimb, știau toți limba rusă și o vorbeau ori de câte ori trebuia. Trebuia mai tot timpul. Să nu vobești rusește la Chișinău era, cel puțin, incomod. Poate doar la piață scăpau cu moldoveneasca. În locurile mai spălate se vorbea în limba omenească. $\mathrm{Cu}$ cât vorbeam mai bine rusește, cu atât mă vedeam mai departe.”36 ilustrează, în fapt, un cod cultural și identitar modificat prin forță, prin producerea unei rupturi de realitatea lingvistică cunoscută.

De remarcat este și faptul că memoria individuală va susține în cazul de față discursul despre o identitate transnațională, care depășește granițele rigide ale unei istorii, astfel încât „Discuţiile despre «ocupanți» - cum erau numiți, mai nou, ușii - continuau. Nu știam de partea cui să fiu. Şcoala îmi era moldovenească, însă rusa îmi plăcea mai mult. Vorbeam rusește în curte, la magazin, în oraș. Adică peste tot. Greta cea cu creta începuse altă vrăjeală. «Limba noastră e limba română, nu moldovenească»», o auzeam vorbind pe coridoare. Copiii o ascultau cu gurile căscate. Într-o zi mam dus să o ascult și eu, însă mare lucru nu am înțeles. De exemplu, spunea ea, pe vremuri, Moldova a fost lipită - așa a spus! - de România. «Cu ce lipită?», am întrebat-o și s-a supărat pe loc. Apoi spunea că rușii i-au ucis pe toți moldovenii deștepțti, lăsându-i vii doar pe cei proști. Aici, mă rog, nu știam ce să zic. Iar la sfârșit ne-a șoptit că taică-său o învățase să citească cu grafie

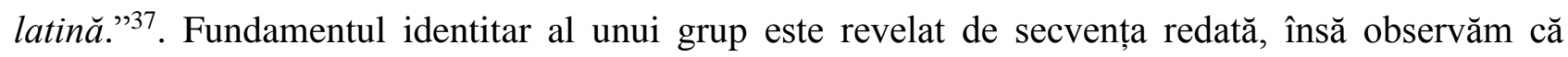
atunci când istoria cauzează o suprapunere forțată a două sau mai multe limbi se va produce nu doar o hibridizare lingvistică, ci va rezulta și o identitate culturală duală. În procesul trecerii de la o limbă la alta, în cazul Lastocikăi se produc mutații identitare, care vor condiționa relaţionarea cu celălalt. A fi mereu între va alimenta și o nevoie de recunoaștere identitară într-un spațiu al hibridizării culturale, motiv pentru care în contextul unei relaxări sociale „Tot mai mulți moldoveni spuneau deschis că au limba lor, cu accentul pe noastră. Limba noastră, limba noastră - de la televizor, la radio, din guri. Pentru unii ruși, acestea au fost primele cuvinte moldovenești care le-au intrat în cap. Drept că și singurele." 38 . Țîbuleac expune în fapt un destin colectiv prin radiografierea unei identități primare în ruptură cum este cea a Lastocikăi. Astfel, traseul existențial al personajului 
feminin redă parcursul istoric al unui spațiu ale cărui granițe au fost constant retrasate. Tocmai aceste redefiniri teritoriale au întreținut sentimentul întrăinării, al rupturii și al dezrădăcinării.

\section{Concluzii}

Așadar, ficționalizarea unei traume transmise intergeneraţional instituie o relaţie cu trecutul. Prin rememorare, se reactivează dialogul cu trecutul, care permite și redarea unei imagini complexe despre felul în care s-a articulat un traseu existențial. Literatura memoriei realizează radiografii care completează sau deturnează reprezentările standardizate de discursul istoriei. În cazul romanului Ruxandrei Cesereanu, „camera” a urmărit destinul unei societăţi mutilate prin teroare, a unei societăţi dezrădăcinate, a unei societăţi private de la dialogul cu alteritatea. În schimb, în romanul Tatianei Țîbuleac am remarcat o demitizare, o demistificare a evenimentelor traumatice. Cele două romane sunt însă convergente, complementare, întrucât ilustrează o relație de interdependență, stabilită între o memorie individuală și una colectivă, ceea ce determină crearea unor spații specifice. Așadar, spațiul descris în romanul Un singur cer deasupra tuturor - un spațiu închis -a generat spaimă, teroare, fiind un spațiu-limită, ce privează omul de libertatea de exprimare. Însă, în romanul Tatianei Țîbuleac am regăsit un spațiu-mobil, configurat din perspectiva personajului feminin, al cărui destin configurează facerea și desfacerea unei lumi.

Totodată, dacă Ruxandra Cesereanu a expus destine care configurează o memorie colectivă traumatică, Tatiana Ţîbuleac a pătruns în imaginarul colectiv despre comunism, însuşindu-şi-l prin configurarea unui spațiu care prinde între granițele sale identități în formare, identități în ruptură. Punerea în oglindă a celor două romane se datorează și faptului că reflectă aceleași imagini cu toate că spațiul de referință este altul. Dacă la Țîbuleac românitatea, adică identitatea etnică mai ales, e disputată în raport cu sistemul comunist, la Cesereanu identitatea socio-culturală e cea reprezentată ca fiind supusă metamorfozei. În definitiv, în Grădina de sticlă există Un singur cer deasupra tuturor, întrucât fragilitatea unei istorii camuflate este depășită prin relevarea unei identități traumatice, purtătoarea unei memorii reconfigurate prin acceptarea traumei ca devenind parte dintrun cod cultural. Astfel, romanul contemporan devine „un roman al reconstrucției indirecte a istoriei prin intermediul instrumentului mnemotehnic. $\mathrm{Nu}$ este un roman memorialistic pentru că memorialistica continuă perpetuarea auto-reflexivității [...], ci un roman al diferitelor procese mnemotehnice, mai mult sau mai puțin directe, mai mult sau mai puțin evidențiate sau ocultate în cotidian." 39 . 


\section{Bibliografie:}

***, Dezbatere: Proza românească în mileniul III (2001-2013), disponibil online pe https://corpult.wordpress.com/2013/11/19/116/?fbclid=IwAR2KJaallbAAL141aEhakI_TTJsPTutXP 786eSbd1mfxzZV-ZbplcWhQC0, accesat la data de 13.10.2019.

Anghel, Oliver, Generația de creație 2000, Pitești, Tiparg, 2013.

Bergson, Henri, Mémoire et vie, textes choisis par Gilles Deleuze, Paris, Presses Universitaires de France, 1975.

Butușină, Elena, Autism și creativitate. Identități narative în proza contemporană, București, Tracus Arte, 2013.

Cesereanu, Ruxandra, Un singur cer deasupra lor, ediția a II-a revăzută și adăugită, București, Polirom, 2015.

Cordoș, Sanda, Lumi din cuvinte. Reprezentări și identități în literatura română postbelică, București, Cartea Românească, 2012.

Diniţoiu, Adina Gabriela I., Evoluţia şi direcţiile prozei româneşti după 1990, disponibil online pe http://cesindcultura.acad.ro/images/fisiere/rezultate/postdoc/rapoarte\%20finale\%20de\%20cercetare \%20stiintifica\%20ale\%20cercetatorilor\%20postdoctorat/lucrari/Dinitoiu_Adina.pdf?fbclid=IwAR1 s5VyGzaZVVUeSvwgefuvVBu8vMX_jgVjQ4aMRdr7RZg8UKGti8RRnA2U, accesat la data de 30.10.2019.

Foster, Jonathan K., Memory: a very short introduction, Oxford University Press, 2009.

Halbwachs, Maurice, Memoria colectivă: eseuri de ieri și de azi, traducere de Irinel Antoniu, Iași, Institutul European, 2007.

Lefter, Ion Bogdan, Despre identitate. Temele postmodernității, Pitești, Paralela 45, 2004.

Mironescu, Andreea, Textul literar şi construcţia memoriei culturale. Forme ale rememorării $\hat{\imath}$ literatura română din postcomunism, disponibil online la http://www.cesindcultura.acad.ro/images/fisiere/rezultate/postdoc/rapoarte\%20finale\%20de\%20cer cetare\%20stiintifica\%20ale\%20cercetatorilor\%20postdoctorat/lucrari/Mironescu_Andreea.pdf?fbcli d=IwAR0ph1xGkkmh0qIkC3_WVk7XWOmDaY24Wwbg0ch96Qhi0T_uveiRU7ITPGg, accesat la data de 30.10.2019.

Oprescu, Florin, Romanul românesc și morfologia puterii, Iași, Institutul European, 2018.

Ricoeur, Paul, Memoria, istoria, uitarea, traducere de Ilie Gyurcsik și Margareta Gyurcsik, Timişoara, Editura Amarcord, 2001.

Simuț, Andrei, Romanul românesc postcomunist între trauma totalitară şi criza prezentului. Tipologii, periodizări, contextualizări, disponibil online la 
http://cesindcultura.acad.ro/images/fisiere/rezultate/postdoc/rapoarte\%20finale\%20de\%20cercetare \%20stiintifica\%20ale\%20cercetatorilor\%20postdoctorat/lucrari/Simut_Andrei.pdf?fbclid=IwAR1N 714zaGkanL3EjRJXUOfc2RajVX78u2zOCRUAU7c8dO9dPTLAsCKNrFQ, accesat la 30.10.2019.

Țîbuleac, Tatiana, Grădina de sticlă: roman, ediția a II-a, Chișinău, Cartier, 2018.

\footnotetext{
${ }^{1}$ Florin Oprescu, Romanul românesc și morfologia puterii, Iași, Institutul European, 2018, p. 197.

2 Sanda Cordoș, Lumi din cuvinte. Reprezentări și identități în literatura română postbelică, București, Cartea Românească, 2012, p. 132-133.
}

3 ***, Dezbatere: Proza românească în mileniul III (2001-2013), disponibil online pe https://corpult.wordpress.com/2013/11/19/116/?fbclid=IwAR2KJaallbAAL141aEhakI_TTJsPTutXP786eSbd1mfxzZVZbplcWhQC0, accesat la data de 13.10.2019.

${ }^{4}$ Idem, ibidem.

5 Adina Gabriela I. Dinițoiu, Evoluţia şi direcţiile prozei româneşti după 1990, p. 7 disponibil online pe http://cesindcultura.acad.ro/images/fisiere/rezultate/postdoc/rapoarte\%20finale\%20de\%20cercetare\%20stiintifica\%20al e\%20cercetatorilor\%20postdoctorat/lucrari/Dinitoiu_Adina.pdf?fbclid=IwAR1s5VyGzaZVVUeSvwgefuvVBu8vMX_j gVjQ4aMRdr7RZg8UKGti8RRnA2U, accesat la data de 30.10.2019.

${ }^{6}$ Oliver Anghel, Generația de creație 2000, Pitești, Tiparg, 2013, p. 47.

${ }^{7}$ Idem, ibidem, p. 15.

${ }^{8}$ Milan Kundera, apud Florin Oprescu, op. cit., p. 195.

${ }^{9}$ Andreea Mironescu, Textul literar şi construcţia memoriei culturale. Forme ale rememorării în literatura română din postcomunism, p. $19, \quad$ disponibil online la http://www.cesindcultura.acad.ro/images/fisiere/rezultate/postdoc/rapoarte\%20finale\%20de\%20cercetare\%20stiintifica \%20ale\%20cercetatorilor\%20postdoctorat/lucrari/Mironescu_Andreea.pdf?fbclid=IwAR0ph1xGkkmh0qIkC3_WVk7X WOmDaY24Wwbg0ch96Qhi0T uveiRU7ITPGg, accesat la data de 30.10.2019.

${ }^{10}$ Ion Bogdan Lefter, Despre identitate. Temele postmodernității, Pitești, Paralela 45, 2004, p. 22.

${ }^{11}$ Elena Butușină, Autism și creativitate. Identități narative în proza contemporană, București, Tracus Arte, 2013 , p. 54.

${ }^{12}$ Idem, ibidem.

${ }^{13}$ Andrei Simuț, Romanul românesc postcomunist între trauma totalitară şi criza prezentului. Tipologii, periodizări, contextualizări, $\quad$ p. $17, \quad$ disponibil online la http://cesindcultura.acad.ro/images/fisiere/rezultate/postdoc/rapoarte\%20finale $\% 20$ de $\% 20$ cercetare $\% 20$ stiintifica $\% 20 \mathrm{al}$ e\%20cercetatorilor\%20postdoctorat/lucrari/Simut_Andrei.pdf?fbclid=IwAR1N714zaGkanL3EjRJXUOfc2RajVX78u2z OCRUAU7c8dO9dPTLAsCKNrFQ, accesat la 30.10.2019.

${ }^{14}$ Sanda Cordoș, op. cit., p. 132.

15 Paul Ricoeur, Memoria, istoria, uitarea, traducere de Ilie Gyurcsik și Margareta Gyurcsik, Timișoara, Editura Amarcord, 2001, p. 77.

${ }^{16}$ Vezi Maurice Halbwachs, Memoria colectivă: eseuri de ieri și de azi, traducere de Irinel Antoniu, Iași, Institutul European, 2007.

${ }^{17}$ Jonathan K. Foster, Memory: a very short introduction, Oxford University Press, 2009, p. 1: „Without it, we would be unable to speak, read, identify objects, navigate our way around our environment, or maintain personal relationships" (traducerea mea).

${ }^{18}$ Florin Oprescu, op. cit., p. 196.

${ }^{19}$ Idem, ibidem, p. 202.

${ }^{20}$ Idem, ibidem.

${ }^{21}$ Andrei Simuț, op. cit., p. 105.

${ }^{22}$ Idem, ibidem, p. 106.

${ }^{23}$ Ruxandra Cesereanu, Un singur cer deasupra lor, ediția a II-a revăzută și adăugită, București, Polirom, 2015 , p. 8.

${ }^{24}$ Idem, ibidem, p. 9.

${ }^{25}$ Idem, ibidem, p. 21.

${ }^{26}$ Idem, ibidem.

${ }^{27}$ Idem, ibidem, p. 31.

${ }^{28}$ Idem, ibidem, p. 32.

${ }^{29}$ Idem, ibidem, p. 213.

${ }^{30}$ Tatiana Țîbuleac, Grădina de sticlă: roman, ediția a II-a, [f.1.], Cartier, 2018, p. 7.

${ }^{31}$ Idem, ibidem, p. 9.

${ }^{32}$ Idem, ibidem, p. 7. 
${ }^{33}$ Idem, ibidem, p. 9.

${ }^{34}$ Idem, ibidem.

${ }^{35}$ Idem, ibidem, p. 19.

${ }^{36}$ Idem, ibidem, p. 41-42.

${ }^{37}$ Idem, ibidem, p. 108.

${ }^{38}$ Idem, ibidem, p. 103.

${ }^{39}$ Florin Oprescu, op. cit., p. 204. 